\title{
ANIMAL-BASED MEASURES: A STEP TOWARDS RIGHTS FOR FARM ANIMALS?
}

\author{
SACHA LUCASSEN ${ }^{1}$ \\ ${ }^{1}$ Center for Animal Defence (CFDF), Copenhagen, Denmark. ORCID: 0000-0003-2456-6319, Email: slu- \\ cassen@yahoo.com
}

\begin{abstract}
While more than ever we are discussing animal rights and considering the possibility to extend the circle of our moral consideration, we are also more than ever inflicting suffering on more animals than in any time in history. This is especially the case for farm animals. This article aims to demonstrate that introducing animal-based measures into the legal system can be a practical and realistic step towards changing the familiar perspective of farm animals as mere commodities into the sentient beings they are.
\end{abstract}

Currently, legislation on farm animals builds on what are called resource-based measures. These measures are not based on the animals but on their environment and the conditions in which the animals are living. They are very compatible with the legal system being relatively easy to assess, less subjective and highly repeatable. However, compliance with resource-based measures does not always mean good animal welfare, since these measures are generally considered to be less well correlated to the experiences of the animal.

Animal-based measures, on the other hand, measure the state of the animal based on the actual animal, its behaviour (e.g. repetitive behaviour, human-animal relationship) and/or appearance (posture, facial expression, body condition).

A change where laws on animals actually require looking at the animals has the potential to improve the relationship to the animals and is an essential shift towards farm animals being regarded as someone and not something. By acknowledging animals as whole sentient beings, we do not just see a complex system of 'behaviours' (e.g. walking), but first and foremost we see a "behaver", a dynamic living being, whose movements are always meaningful and psychological expressive.

In conclusion, animal-based measures force us to look at animals and recognize that they are able to feel pain, love, joy, loneliness and fear. Implementing animal-based measures for farm animals makes us, in a practical and realistic way, take those ani- 
mals that are mostly considered as mere commodities, into our moral consideration, and unveils aspects of their sentience, which are currently hidden by the law.

KEYWORDS: animal welfare, animal rights, animal-based measures, resource-based measures

\section{INTRODUCTION}

Humans and animals both belong to the biological world and share the natural world. They have lived in co-existence for decades, but in recent times humans have taken increasing procession of animals. This procession is based on a view of human supremacy and an anthropocentric perspective which have led to humans inflicting suffering, on more animals than in any time in history. The most evident example of this is animals used in intensive farming since intensive methods of farming are causing daily suffering for the billions of animals we raise for food around the world.

The number of farm animals reared for food globally has risen to just over 70 billion a year, and two out of three farm animals are now reared intensively (Compassion in World Farming 2017:3).

Farm animals are for many considered mere products to be used, traded, bought, transported and discarded or slaughtered. However, in recent years, consumers have become increasingly concerned about the way animals are raised, for public health, food safety and animal welfare reasons. This concern has displayed an increased interest to protect the farm animals and make sure we regulate around our use of them.

The interest in animal welfare can be seen in the Special Eurobarometer 442 on the Attitudes of Europeans towards Animal Welfare which demonstrated an increasing interest in society for better welfare for animals (Eurobarometer 2016). The support for animal welfare was not restricted to a small number of member states or any particular corner of Europe. Interest in animal welfare was proven robust throughout the EU with $82 \%$ stating they believe farm animals should be better protected than they are now (Eurobarometer 2016: 4).

This interest and concern in animal welfare has led to an increase in the number of legal acts. Nevermore than in present time have there been adopted laws on the protection of animals. However, millions of animals continue to suffer, and some would argue there has also never been more suffering of animals than there is today. This is often stated because of the increased use of animals in intensive farming systems (Francione 2008). As seen in the Eurobarometer there is an increasing concern regarding the farm animals' restricted freedom of movement and ability to exercise natural behaviour due to the way the animals are housed, treated, transported and killed. This concern has led to a movement in a society where many citizens are demanding a change on the use of farm animals.

Farm animals are considered both "sentient beings" and "tradable goods" within the legal framework of the European Union. This dual status creates tension as the traditional paradigm for regulating animals in the Union has been primarily on animals as economic entities. The change in concern of farm animals has given rise to a paradox of considering the well-being of animals as "sentient beings", while they are 
still considered "agricultural” products within the Treaty.

This article aims to demonstrate that introducing specific animal-based measures into the legal system can be a practical and realistic step towards changing the familiar perspective of farm animals as mere commodities into the sentient beings they are.

\section{ANIMAL PROTECTION IN THE EU}

Animal welfare legislation on farm animals has developed and expanded its coverage since the first EU legislation on the welfare of animals was adopted in 1974. Today the European Union is said to have some of the world's highest animal welfare standards when it comes to farmed animals (Special report No 31, 2018). In general farm animals are protected by a minimum standard of welfare, and this standard is set at EU-level by the Common Agricultural Policy (CAP) - the EU's support system for agriculture. EU legislation covers with provisions the farming of poultry, calves and pigs as well as, for all species, transport and slaughter operations. In particular, the EU has banned traditional cages for laying hens and requires group housing for pregnant sows. Animal welfare under the CAP began as an agricultural production policy designed to ensure food supplies and agricultural incomes.

The concept of animal welfare is enshrined in the Treaty on the Functioning of the European Union (TFEU), which recognizes animals as sentient beings:

In formulating and implementing the Union's agriculture, fisheries, transport, internal market, research and technological development and space policies, the Union and the Member States shall, since animals are sentient beings, pay full regard to the welfare requirements of animals, while respecting the legislative or administrative provisions and customs of the Member States relating in particular to religious rites, cultural traditions and regional heritage.

This offers a potential foundation for an approach to animal welfare in the EU that is motivated by a moral concern for the welfare of individual animals. It implies a move from an economic understanding of animals as "products" - with an extrinsic value for humans - to a moral understanding of the value attached to the needs of animals (Sowery 2018:56).

\section{The legal protection of animal sentience}

Animal sentience is a contested concept; it implies a holistic approach to the needs of animals on the understanding that they are able to experience several emotions associated with pleasurable states such as joy, and aversive states such as pain and fear (Broom 2007:100). Although the scientific research in this area is equivocal, the consensus is that most animals used for human purposes are sentient and thereby capable of feeling both positive and negative feelings. The recognition of animal sentience has fostered the question how to protect these sentient beings in a legal context. There can be recognized two main legal approaches to the protection of animal sentience: animal welfare and animal rights.

The first approach to protect animals is the welfare-based approach that deals with 
animals as objects - the property of legal persons - that are to be protected. In the nineteenth century, the animal welfare position became popular and still to this day is the dominant view of society and therefore, the legal foundation on animals. The animal welfare approach is based on the fact that we have a moral and legal obligation to treat animals humanely and to avoid imposing unnecessary suffering on them. The primary focus of animal welfare is hereby the regulation of animal treatment (Francione 2008).

The second approach is the rights-based approach under which animals should be protected through legal rights (Sunstein \& Nussbaum 2005). It means recognizing that animals are not ours to use - for food, clothing, entertainment, or experimentation.

\section{Rights versus welfare}

It is essential to acknowledge the critical distinction between animal rights and animal welfare - which revolves around ethical questions as to whether animals should be killed for human consumption or used for certain activities. While both animal rights and animal welfare positions find their basis in the recognition of animals as "sentient beings", they differ as to what the recognition of sentience should entail in practice. For animal rights supporters, animal sentience requires equal consideration to human sentience, and therefore no form of animal use, regardless of how 'humanely' animals are treated, can be justified. By contrast, welfare supporters focus on particular tenets of the concept of sentience, such as hunger, pain, fear and joy. To this extent, they often sustain the species divide between humans and animals to justify the use of animals (Graça 2014: 749).

The European Union employs an animal welfare approach in protecting animals as sentient beings. This means the laws regulate around farm animals as a property that exists for the benefit of humans, while we have to ensure their basic needs are met and prevent unnecessary suffering and cruel treatment (Regulation No 1099/2009 on the protection of animals at the time of the killing, OJ 2009 L 303. and Article 3 Regulation 1/2005 of 22 December 2004 on the protection of animals during transport and related operations and amending Directives 64/432/EEC and 93/119/EC and Regulation No $1255 / 97$ OJ L 3, 5.1.2005, p. 1-44, lays down an overarching requirement that transporters must not transport any animal, or cause any animal to be transported, in a way which is likely to cause "injury or undue suffering" to that animal).

\section{ASSESSING ANIMAL WELFARE: RESOURCE-BASED MEASURES VERSUS ANI- MAL-BASED MEASURES}

When it comes to assessing animal welfare at the farm level, two broad categories of measures can be distinguished. The first category contains the resource-based measures, i.e. input assessment; they measure the conditions in which the animals are living, e.g. stocking densities, cubicle size, and flooring. They are input factors or risk factors affecting animal welfare.

The second category contains the animal-based measures, i.e. output assessment; 
they measure the welfare state of the animal, e.g. behaviour, injuries and diseases. Thus, they assess the outcome or effect of a number of risk factors.

Because resource-based measures are generally less subjective than animal-based measures, often more accessible to audit and highly repeatable, these measures are more frequently included in animal welfare legislation. However, resource-based measures are generally considered to be less well correlated to the experiences of the animal (EFSA 2012a). The reason for this is that many factors might affect the welfare of the animals, which makes it difficult to include them all in legislation.

The current legislation on farm animals builds on resource-based measures. However, because of the weak correlation between the actual welfare of the animals and resource-based measures, the European Union has shown considerable interest in making use of animal-based measures. The interest in using animal-based measures at EU-level has been outlined in the European Union Strategy for the Protection and Welfare of Animals 2012-2015. It suggests a new EU legislative framework for animal welfare that may include the use of scientifically validated animal-based welfare measures to complement prescriptive requirements, thereby simplifying the legal framework and allowing flexibility to improve the competitiveness of livestock producers (EFSA 2012b:4).

\section{Qualitative Behavior Assessment as an example of an animal-based measure}

The European Union and has funded several research projects in the field of animal-based measures. One EU funded project is Welfare Quality ${ }^{\circledR}$, which is the largest European project to focus primarily on animal-based measures. It has been influential in developing a standardized system for the assessment of animal welfare.

In the Welfare Quality ${ }^{\mathbb{R}}$, several animal-based measures are validated for inclusion in the welfare assessment. One animal-based measure from the project is Qualitative Behavior Assessment (QBA), which was concluded to be satisfactory with regard to inter-observer reliability, having high feasibility and being very relevant for the welfare of animals. It, therefore, should part of the Welfare Quality monitoring tool (Wemelsfelder, Millard, De Rosa, Napolitano 2009).

QBA is a whole-animal approach, and the underlying premise is that human observers can integrate perceived behavioural details and signals to judge an animal's behavioural expression, using qualitative descriptors (e.g. relaxed, anxious) that reflect the animals' affective (emotional) state (Wemelsfelder 1997 \& Wemelsfelder 2007). In the Welfare Quality ${ }^{\circledR}$ the QBA as a method relies on the ability of human observers to integrate perceived details of behaviour, posture, and context into descriptions of an animal's style of behaving or "body language”, using descriptors such as "tense”, "frustrated" or "content". Such terms have an expressive, emotional, connotation and provide information that is directly relevant to animal welfare. Carrying out this observation method, the observer watches the animals and marks if he finds the term to be, e.g. absent or dominant for the animals under the study. The Welfare Quality ${ }^{\circledR}$ concludes that the application of QBA on-farm is highly feasible and easy to learn; however, assessors must be experienced in observing cattle and be given additional 
training on cattle expressions.

\section{THE ANIMAL AS SUBJECT}

Qualitative Behavior Assessment was initially developed with the aim of providing more space for the animal's perspective - the "animal-as-subject" - in scientific studies of animal emotion and welfare. Pioneering field ethologists such as Jane Goodall and Cynthia Moss, in their life-long studies of chimpanzees and elephants, used it to describe the characters and emotions of the animals they knew so well. QBA's aim was to extend this work, proposing that from a whole-animal perspective, qualitative terms such as "anxious" and "relaxed" do not merely describe "behavioural style", but also address what animals actually, subjectively, feel.

The starting point is that animals are whole sentient beings and that when we acknowledge them as such. We do not just see a complex functional system of 'behaviours' (e.g. walking), but first and foremost we see a "behaver", a dynamic living being, whose movements are always meaningful and psychologically expressive. Scientists are trained to measure what animals do physically (e.g. walk, sniff, rest), but it is in observing how animals do what they do, that we can get closer to how they experience the situation they are in. An animal can walk, fly or swim around in a way that is relaxed and curious, or tense and anxious; the behaviour is the same, but the expressive quality differs, providing a window on the animal's feelings. QBA asks people to interpret and quantify these qualities and then uses statistical analysis to identify patterns of expressivity that describe how individual animals, or animals in groups, can differ in their emotional response to a situation.

\section{Qualitative Behavior Assessment in the legal system}

In the legal system, we regulate farm animals as property and only provide them only the minimum to meet their basic needs. I.e. the welfare of pigs is assured by Council Directive 2008/120/EC applies to all categories of pig and lays down minimum standards for their protection. Council Directive 2008/119/EC prohibits the use of confined individual pens after the age of eight weeks. The Directive, amongst other things, sets out minimum dimensions for individual pens and for calves kept in a group.

There is a shared belief, however, that the welfare of animals encompasses more than just the absence of suffering. QBA regards animals as sentient beings capable of having a variety of feelings which all affect their welfare.

QBA differs fundamentally from the current legislation with resource-based measures where the focus is on the input of the animals. With QBA time is taken to carefully observe animals and the quality of their expressions, which first of all give us a more in-depth insight into their welfare but also provides a profound change in the way we perceive these animals.

Only limited amount of research has been done on the implementation of animal-based measures in the legal system. It can be stated, however, that it is unlikely that animal-based will replace resource-based measures because of legal challenges. 
Nevertheless, animal-based measures can be implemented in the legal system in many forms, as a top-up on resource-based measures. Considering the European Union's interest in making use of animal-based measures because of their advantages, it is likely we will see the implementation of them in future legislation.

\section{CONCLUSION}

The current legislation on farm animals builds on resource-based measures which are implemented to prevent and predict welfare issues. They are regarded as minimum standards that the farmer must meet. However, while resource-based measures are suitable to prevent poor welfare and identify risk factors, animal-based measures are perceived as better correlated to the actual state of the animal. Therefore, it seems that animal-based measures can better make sure the objectives of the animal welfare legislation are achieved, and the level set by the legislators can be reached.

The purpose of this article was to demonstrate how animal-based measures have the potential to also serve as a step for farm animals having rights. These measures force us to look at animals in a different way than ordinary resource-based measures. They enable us to recognize that farm animals are able to feel pain, love, joy, loneliness and fear. Implementing these measures into legislation requires farmers and professional assessors to investigate the emotional state and behaviours of farm animals. This provides a profound change from the current legislation and has the potential to perceive farm animals as the living sentient beings they are stated to be in the Lisbon Treaty.

In conclusion, implementing animal-based measures for farm animals makes us, in a practical and realistic way, take those animals that are mostly considered as mere commodities, into our moral consideration, and unveils aspects of their sentience, which are currently hidden by the law.

FUNDING: This research received no external funding.

CONFLICT OF INTEREST: The author declares no conflict of interest.

\section{REFERENCES}

Broom, Donald. 2007. "Cognitive ability and sentience: Which aquatic animals should be protected?” DAO Volume 75(2): 99-108.

Compassion in World Farming. 2017. Strategic Plan 2013-2017 for Kinder, Fairer Farming Worldwide. Retrieved August 1, 2019 (https://www.ciwf.org.uk/media/3640540/ ciwf_strategic_plan_20132017.pdf).

European Food Safety Authority. 2012a. "Scientific Opinion on the use of animal-based measures to assess welfare of dairy cows.” EFSA Journal 10(1): 1-85. DOI: https:// doi.org/10.2903/j.efsa.2012.2512.

European Food Safety Authority. 2012b. European Union Strategy for the Protection and Welfare of Animals. Retrieved August 1, 2019 (https://ec.europa.eu/food/animals/ welfare/strategy_en). 
European Commission. 2016. Special Eurobarometer 442 Attitudes of Europeans towards Animal Welfare. Retrieved July 28, 2019 (https://data.europa.eu/euodp/en/data/ dataset/S2096 84_4_442_ENG).

European Court of Auditors. 2018. Special report No 31/2018: Animal welfare in the EU: closing the gap between ambitious goals and practical implementation. Retrieved August 1, 2018 (https://www.eca.europa.eu/en/Pages/DocItem.aspx?did=47557).

Francione, Gary. 2008. Animals as Persons: Essays on the Exploitation of Nonhuman Animals. New York: Columbia University Press.

Graça, João. Maria Manuela Calheiros and Abilio Oliveira. 2014. "Moral Disengagement." Journal of Agricultural and Environmental Ethics 27(5): 749-765.

Nussbaum, Martha and Cass Sunstein. 2005. Animal rights: current debates and new directions. Oxford: Oxford University Press.

Sowery, Katy. 2018. "Sentient beings and tradable products: the curious constitutional status of animals under union law." Common Market Review 55(1): 55 - 99.

Wemelsfelder, Françoise. 1997. "The scientific validity of subjective concepts in models of animal welfare.” Applied Animal Behaviour Science 53(1-2): 75-88.

Wemelsfelder, Françoise. 2007. "How animals communicate quality of life: the qualitative assessment of animal behaviour." Animal welfare 16(5): 25-31.

Wemelsfelder, Millard, De Rosa, Napolitano. 2009. "Qualitative Behaviour Assessment.” Pp. 215-224 in Assessment of Animal Welfare Measures for Dairy Cattle, Beef Bulls and Veal Calves, edited by B. Forkman and L. Keeling. Uppsala: SLU Service.

\section{BIOGRAPHICAL NOTE}

Sacha Lucassen is a qualified lawyer and holds a master in Animal Law. She is the organiser and lecturer of the Summer Course on Animal Law in Denmark at Aarhus University. Sacha is also the chairman and co-founder of Center for Animal Defence (CFDF).

OPEN ACCESS: This article is distributed under the terms of the Creative Commons Attribution Non-commercial License (CC BY-NC 4.0) which permits any non-commercial use, and reproduction in any medium, provided the original author(s) and source are credited. 